\title{
PERCEPÇÃO AMBIENTAL DE DOCENTES EM ESCOLA RURAL NO ESTADO DE SERGIPE
}

\author{
Cristiano Cunha Costa', Paulo Sérgio Maroti² \\ ${ }^{1}$ Engenheiro Florestal (UFS), Especialista em Educação Ambiental e Recursos Hídricos (USP), Mestre em Agroecossistemas \\ (UFS). Email: cristianocunha1982@hotmail.com \\ 1Prof. Adjunto/UFS/Campus Prof. Alberto Carvalho/Itabaiana-SE. Email: dpsm@ufs.br
}

http://dx.doi.org/10.5902/223613087485

\section{RESUMO}

A questão ambiental torna-se ainda mais presente a cada dia, diante da pressão humana sobre os recursos ambientais. Dessa maneira, torna-se necessário o estudo da percepção ambiental, como ferramenta de educação ambiental, favorecendo uma discussão sobre a temática ambiental de forma interdisciplinar. Para isso, foram entregues 2 folhas de papel branco, sendo solicitado o desenho da situação atual da barragem e como estaria a barragem daqui a 10 anos. Em seguida, no verso da folha, comentassem sobre os desenhos. Foram observados, como situação atual, mapas mentais com landmarks associados à irrigação, consumo doméstico, às atividades turísticas desenvolvida na barragem em bares e meios de transporte, com a presença de animais, sem vegetação ciliar, de água de coloração escura e sem infra-estrutura para atender a demanda de visitação. Com relação à situação da barragem daqui dez anos, observou-se landmarks tipicamente de um ambiente em harmonia com o ser humano. Observa-se uma água limpa, com peixes, vegetação ciliar e a figura humana unida em favor do meio ambiente. Por outro lado, nota-se landmarks com perfis pessimistas, devido ao uso abusivo dos recursos naturais, o descaso e a falta de consciência das pessoas, como possíveis causas do ambiente desequilibrado. Portanto, é evidente a preocupação com a barragem em estudo, tanto com a sua situação atual como também com sua situação futura, destacando-se a necessidade de adoção de estratégias de recuperação e preservação do recurso hídrico.

Palavras-chaves: mapas mentais, landmarks, recurso hídrico.

\begin{abstract}
The environmental issue becomes even more present every day in the face of human pressure on environmental resources. Thus, it becomes necessary to study the environmental perception, as a tool for environmental education, encouraging a discussion about environmental issues in an interdisciplinary manner. For this, we delivered 2 sheets of white paper, and requested the design of the current status of the dam and the dam would be like 10 years from now. Then, in the back of the sheet, give us feedback about the designs. Were observed, as the current situation, mind maps with landmarks associated with irrigation, domestic, tourist activities developed in the dam in bars and transport facilities, with the presence of animals without riparian vegetation, water and dark colored without infrastructure structure to meet the demand for visitation. Regarding the situation of the dam in ten years, we observed landmarks typically an environment in harmony with humans. There is
\end{abstract}


a fresh water, fish, riparian vegetation and human figure united in favor of the environment. Moreover, note landmarks with profiles pessimistic, due to overuse of natural resources, the neglect and lack of awareness of the people, as possible causes of the unbalanced environment. So clearly the concern with the dam under study, both with their current situation as well as future situation, highlighting the need to adopt strategies for recovery and preservation of water resources.

Keywords: mind maps, landmarks, water resource.

\section{INTRODUÇÃO}

A questão ambiental torna-se ainda mais presente a cada dia, diante da pressão humana sobre os recursos ambientais. Os recursos hídricos são recursos naturais de fundamental importância no que tange a geração de energia, irrigação, pesca, turismo, abastecimento doméstico, dentre outros.

A água da Barragem da Ribeira é usada para a irrigação de culturas; abastecimento das comunidades e para o lazer nos finais de semana e feriados. A utilização de água de qualidade ruim traz prejuízos e diminui a qualidade de vida da população urbana e rural.

Diante dos problemas ambientais, torna-se de relevante a importância a participação de professores nas atividades de educação ambiental, sendo possível trabalhar o meio ambiente de forma interdisciplinar, fazendo ligação entre todas as disciplinas e abandonando a idéia de que os conhecimentos das disciplinas sejam trabalhados de forma fragmentada (como de costume pelas escolas locais).

NIDELCOFF (1979) ao explicar o que é o Estudo do Meio, considera o Meio como realidade física, biológica, humana que nos rodeiam e que se ligam de maneira direta por meio da experiência; quanto ao Estudo, esse pode apresentar valores e gradações diferentes: aproximar-se afetivamente, descobrir coisas, exprimi-las, explicá-las, analisá-las. Já para PONTUSCHKA (1994) um estudo do meio pode variar "desde uma saída de estudantes e professores" com o objetivo de entretenimento, até "trabalhos interdisciplinares que demandam pesquisa de campo, bibliográfica, iconográfica", levando a um investimento/necessidade de trabalho tanto individual quanto coletivo.

Já a percepção ambiental é definida por FAGGIONATO (2005) como "uma tomada de consciência do ambiente pelo homem", ou seja, como se auto-define, perceber o ambiente que se está localizado, aprendendo a protegê-lo e cuidá-lo da melhor forma.

Cada indivíduo percebe, reage e responde diferentemente frente às ações sobre o meio. As respostas ou manifestações são, portanto, resultado das percepções, dos processos cognitivos, julgamentos e expectativas de cada indivíduo. Embora nem todas as manifestações psicológicas sejam evidentes, são constantes, e afetam nossa conduta, na maioria das vezes, inconscientemente. Assim, o estudo da percepção ambiental é de fundamental importância para que possamos compreender melhor as inter-relações entre o homem e o ambiente, suas expectativas, satisfações e insatisfações, julgamentos e condutas (FAGGIONATO, 2005).

Para HIGUCHI \& AZEVEDO (2004) as capacidades e experiências pessoais são formas de pensar que nos fazem serem distintos uns dos outros, de modo que, diante de uma mesma situação, cada pessoa tem uma experiência única de percepção, que contribui para formar suas representações, idéias e concepções sobre o mundo. 
KRASILCHIK (1986) expressa que a base dessa diversidade de percepções sobre as causas da degradação do meio e suas soluções, por sua vez, reside na variedade de pontos de vista sobre o processo de desenvolvimento e sobre o conceito de qualidade de vida, que não podem ser padronizados, mas dependem das aspirações de cada população, de cada comunidade.

Do ponto de vista científico, é interessante notar como o conceito de percepção ambiental tem estabelecido conexões entre um estudo sobre o meio físico, próximo aos métodos da geografia, visando promover uma reflexão sobre as relações desse meio com a subjetividade, própria do instrumental psicológico.

Uma crítica epistemológica ao conceito de percepção ambiental suscita, então, a pergunta sobre até que ponto os estudos de percepção ambiental são instrumentos válidos para a "escuta das comunidades" e como a adoção de determinadas perspectivas metodológicas pode expressar os compromissos ideológicos dos agentes envolvidos na administração de áreas protegidas.

Discutir o conceito de percepção ambiental não é, portanto, uma questão de dizer quais das representações parecem corresponder melhor à realidade, mas elucidar as perspectivas científicas, sociais ou políticas veiculadas através da utilização desse conceito.

Para FERRARA (1993), a percepção ambiental é definida como a operação que expõe a lógica da linguagem que organiza os signos expressivos dos usos e hábitos de um lugar. É uma explicitação da imagem de um lugar, veiculada nos signos que uma comunidade constrói em torno de si. Nesta acepção, a percepção ambiental é revelada mediante uma leitura semiótica da produção discursiva, artística, arquitetônica etc. de uma comunidade.

Quanto à metodologia para se avaliar a percepção, JACOBI et al. (2004) utilizaram questionários para avaliar o perfil de percepção ambiental individual em unidades de conservação com diferentes grupos etários, tendo sido observado que, apesar da diferença de faixa etária amostral, a percepção foi expandida e aguçada por atividades de sensibilização ambiental.

A percepção e a interpretação dos níveis e dimensões das realidades ambientais, das singularidades e da importância do patrimônio paisagístico, das atitudes e condutas humanas, dos valores ambientais devem contribuir, essencialmente, para a compreensão das transformações visíveis e não-visíveis, tangíveis ou não, da paisagem, percebida e interpretada como patrimônio de um povo, de um país, legado das futuras gerações, considerando-se as várias instâncias e conjunturas, pois um horizonte de possibilidades individuais e coletivas é desvendado numa expressão de valores locais, regionais e universais (GUIMARÃES, 2007).

Diversas são as formas de se estudar a percepção ambiental: por meio de questionários, mapas-contorno, mapas-mentais, representação fotográfica, etc. Existem ainda trabalhos em percepção ambiental que buscam não apenas o entendimento do que o indivíduo percebe, mas promover a sensibilização, bem como o desenvolvimento do sistema de percepção e compreensão do ambiente.

Elucidar como a utilização do conceito de percepção ambiental tem se inserido nesses debates é uma tarefa importante para a democratização da ciência e dos saberes, e para uma reflexão sobre instrumentos que dispomos e o quanto estes são adequados para garantir a escuta às comunidades na administração de áreas protegidas, visando garantir maior qualidade ambiental para todos.

A questão ambiental é, então, apontada como elemento comum a ser contemplado por diferentes correntes filosóficas e seus respectivos métodos, presentes no processo de conhecimento 
dos problemas sócio-ambientais atuais. Os métodos de interpretação da realidade surgem, nesse contexto, como a via de relacionamento entre essas formas de saber (GUARIM, 2002).

Este trabalho tem como objetivo geral promover o monitoramento sócio-ambiental participativo da qualidade da água da barragem por alunos de uma escola pública do povoado do entorno da Barragem Ribeira, visando subsidiar discussões sobre tal problemática.

\section{METODOLOGIA}

\subsection{Caracterização da área de estudo}

A Escola Municipal Profa. Anailde Santos de Jesus está localizada no Povoado ${ }^{1}$ Cajaíba, zona rural do município de Itabaiana, estado de Sergipe.

As atividades foram realizadas com 5 professores que lecionam no 8o ano, sendo que a barragem de mesmo nome do Povoado foi utilizada como instrumento de estudo da percepção dos

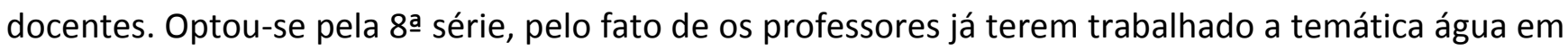
sala de aula.

Para o estudo da percepção ambiental, foram entregues 2 folhas de papel branco (A4), sendo solicitado para que fossem colocados os nomes e em uma delas, fosse desenhado a situação atual da barragem e no verso da folha, que o professor comentasse o próprio desenho.

Com a segunda folha, foi solicitado que os professores imaginassem como estaria a barragem daqui a 10 anos e representassem no papel. Em seguida, no verso da folha, comentassem sobre o desenho representado. Os desenhos foram feitos com lápis de cor, tendo a liberdade para a escolha das cores na confecção dos desenhos. Todos conhecem a barragem e nenhuma informação lhes foi oferecida visando não influenciar nos desenhos.

BARRAZA (1999) propõe a mesma metodologia para a análise da percepção do ambiente de crianças com idade escolar de 7 a 9 anos em uma escola do México (ambiente rural) e em uma da Inglaterra (ambiente urbano). Os resultados obtidos foram de conhecimento sobre a problemática ambiental representados nos desenhos para ambos os grupos amostrados, mas diferiram quanto ao pessimismo relacionado ao futuro. As crianças de áreas urbanas (Inglaterra) são mais pessimistas, enquanto que as crianças que residem e estudam em meio rural (México), portanto mais próximas a natureza, tiveram representações muito mais otimistas relacionado a um futuro próximo.

Para analisarmos os desenhos ou mapas mentais utilizou-se o conceito dos landmarks ou marcos conceituais simbólicos, denominados por Niemeyer (1994).

\footnotetext{
${ }^{1}$ Povoado - Localidade que tem a característica definidora de Aglomerado Rural Isolado e possui pelo menos 1 (um) estabelecimento comercial de bens de consumo freqüente e 2 (dois) dos seguintes serviços ou equipamentos: 1 (um) estabelecimento de ensino de $1^{\circ}$ grau em funcionamento regular, 1 (um) posto de saúde com atendimento regular e 1 (um) templo religioso de qualquer credo. Corresponde a um aglomerado sem caráter privado ou empresarial ou que não está vinculado a um único proprietário do solo, cujos moradores exercem atividades econômicas quer primárias, terciárias ou, mesmo secundárias, na própria localidade ou fora dela (IBGE, 2009).
} 


\section{RESULTADOS E DISCUSSÃO}

\subsection{Mapas mentais e situação atual da barragem}

Mapas mentais são desenhos a respeito de um determinado tema, servindo como ferramenta para o estudo da percepção ambiental de um indivíduo.

No atual trabalho, optou-se pelo uso de mapas mentais, com destaque para os landmarks, visando entendermos as relações simbólicas, especificamente da comunidade discente e docente quanto ao corpo d'água local. Dessa forma, segundo ALLEN et. al. (1979) apud MAROTI (2002) o termo landmark é considerado como um ponto de identificação ambiental, opcionalmente definido, com implicações perceptuais cognitivas e ambientais.

Ao ser solicitado a representação dos desenhos a respeito da barragem, elas já manifestavam suas opiniões, falando que a situação é preocupante ressaltando a importância de estudos na área para que possam saber a real situação da água, uma vez que o recurso é utilizado para agricultura e abastecimento da DESO (Companhia de Saneamento de Sergipe).

Os professores construíram seus mapas mentais representando os landmarks associados principalmente ao uso do corpo d'água e da degradação ambiental local. Na figura 01, pode-se observar a prática de irrigação de culturas no povoado, ao consumo doméstico e impactos negativos, devido às ações antrópicas associadas às atividades de lazer típicas dos finais de semana. 


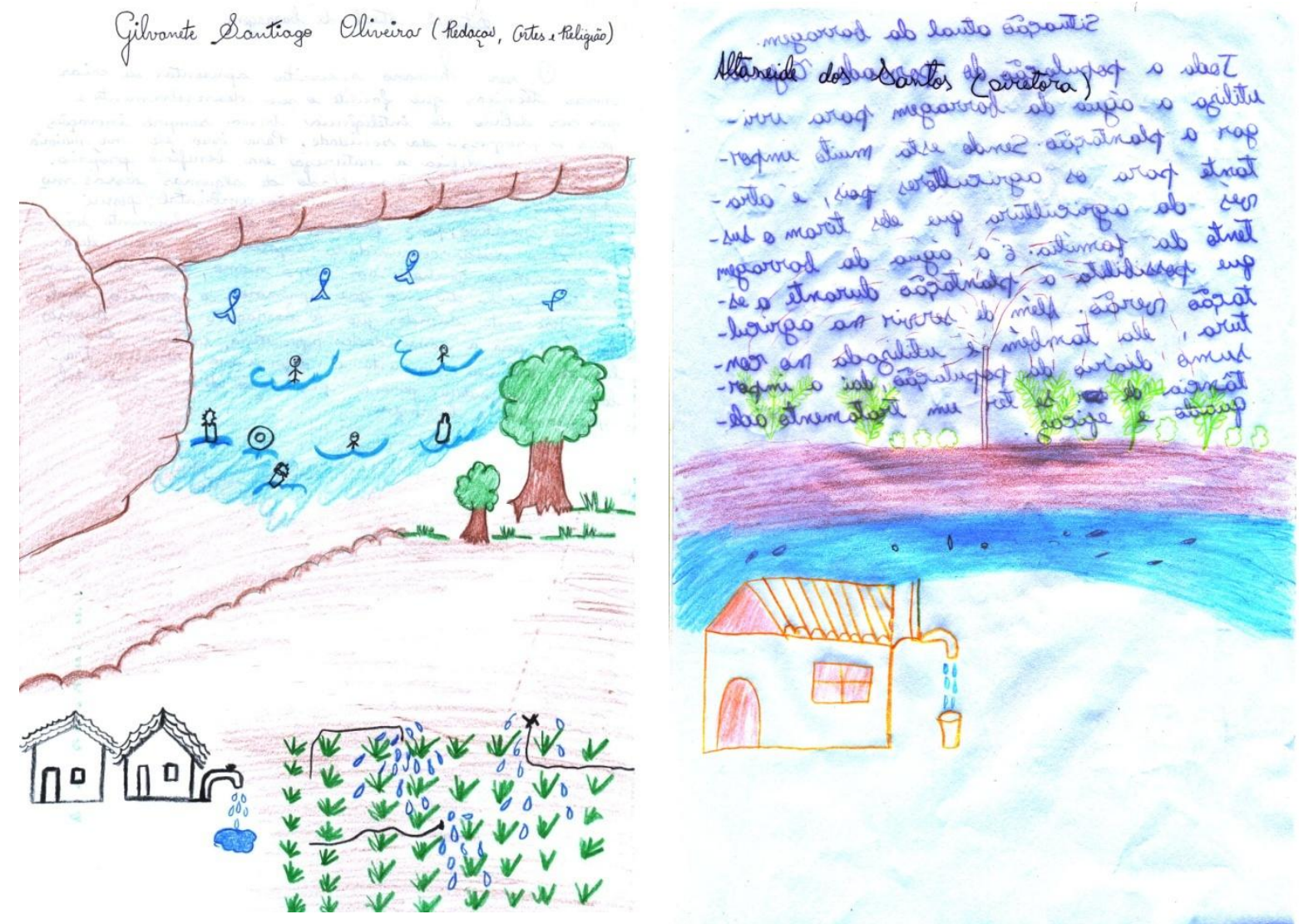

Figura 01. Mapas mentais demonstrando os usos atuais do corpo d'água da Cajaíba. Esquerda: No corpo d'água - Lixo deixado pelas atividades ligadas ao turismo e a utilização da irrigação para a lavoura; Direita: Corpo d'água poluído por ação antrópica e caneleta ajustada no telhado da casa para captura de água.

Em relato abaixo feito por um professor, pode-se observar a relevância desse corpo d'água para a vida da comunidade:

“... (sua construção) favoreceu o desenvolvimento sócio-econômico dessa comunidade (Cajaíba). Por meio dela, a agricultura ganhou um novo rumo, devemos levar em consideração ao turismo que aprimorou o comércio local. Não resta dúvidas que a barragem trouxe diversos benefícios para a comunidade: agricultura, economia, turismo, lazer, etc. o que nos resta é fazer uma ressalva: trabalhar a comunidade para a preservação do meio ambiental, especificamente, a barragem" (professora de redação, artes e religião).

Nos mapas mentais, pode-se observar símbolos de destaque relacionados às atividades turísticas desenvolvida na barragem em bares e meios de transporte, com a presença de animais, ausência de mata ripária/ciliar, água com coloração escura e sem infra-estrutura para atender a demanda de visitação, hábito costumeiro dos finais de semana e feriados (figura 02). 

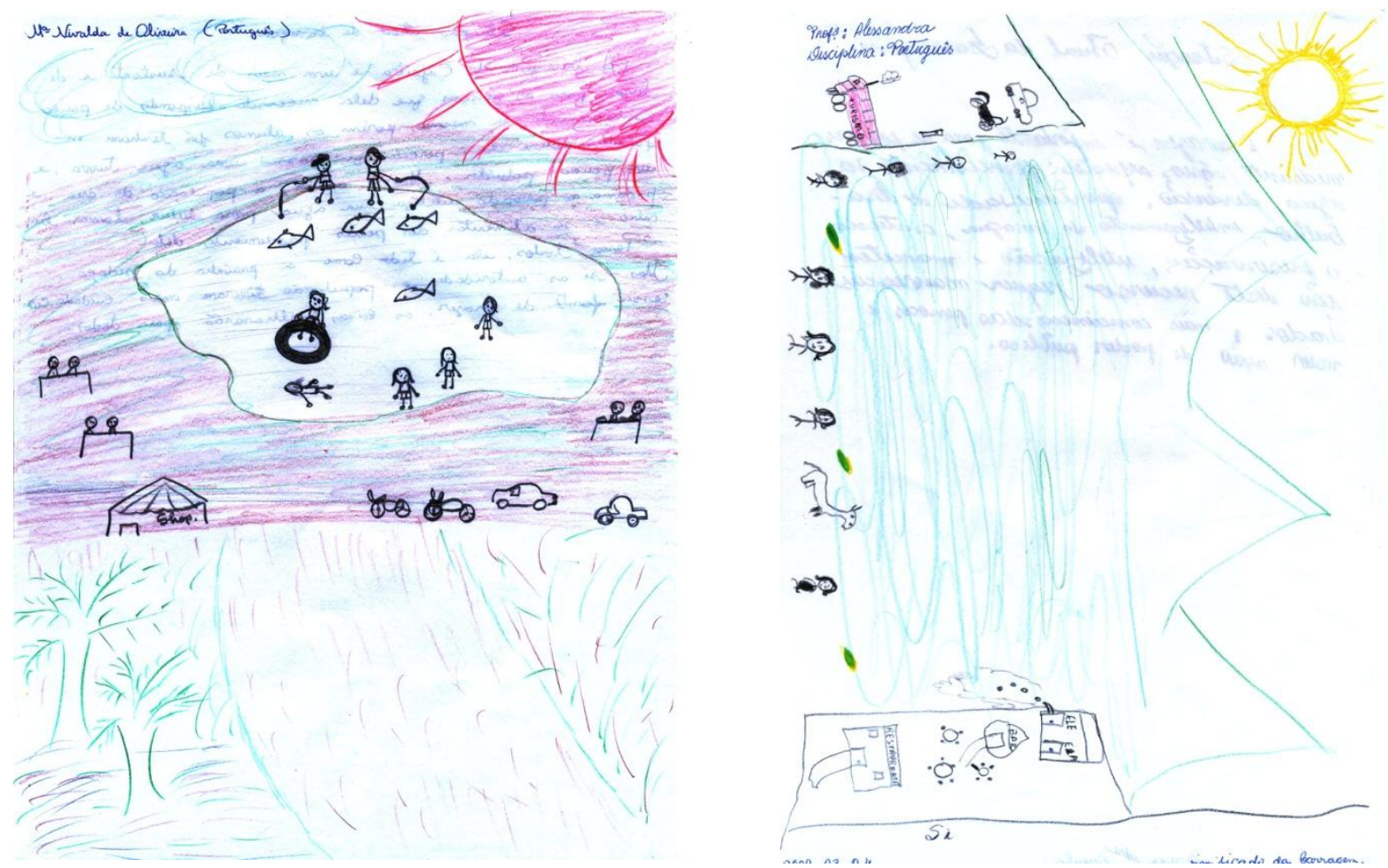

Figura 02. Mapas mentais representando as atividades turísticas de acordo com a percepção de professores da escola próxima ao corpo d’água estudado.

Uma professora comenta sobre a qualidade da água da barragem da Cajaíba ao relatar que:

"A nossa barragem está muito poluída, está precisando de cuidados especiais, pois as sujeiras dos esgotos e dejetos de animais está sendo despejado na barragem. E toda essa água nós bebemos. As pessoas vai tomar banho e joga lixo na água, lava animais. Nós precisamos orientar as pessoas para não jogar lixo na água" (professora de história e geografia).

\subsection{Mapas mentais e situação futura da barragem}

Os mapas mentais representam a percepção das professoras com relação à situação da barragem para daqui a uma década. Na figura abaixo (figura 03), pode-se observar landmarks tipicamente associados a um ambiente em harmonia com o ser humano. Água limpa com peixes, mata ripária/ciliar e a figura humana unida em favor do meio ambiente. 


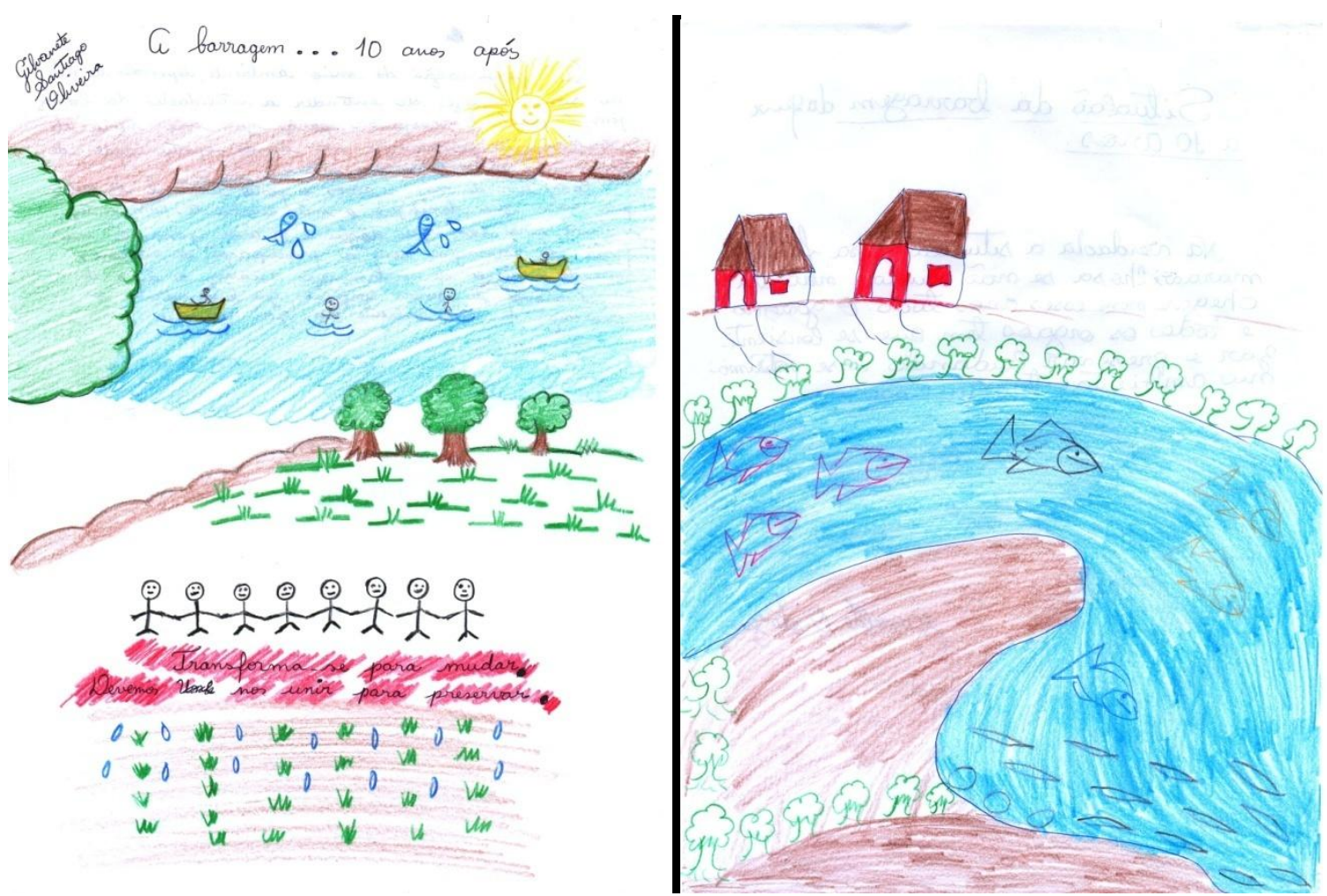

Figura 03. Mapa mental para uma situação futura da barragem Cajaíba denotando otimismo.

O professor de história e geografia relata:

"daqui a uma década, se todos participarem de um trabalho de conscientização, teremos uma água limpa e cristalina para uso das famílias"

Uma das professoras de português comenta que prefere ser otimista, pois as pessoas terão mais educação e melhor cuidado pela barragem e acrescenta quanto ao futuro:

"Haverá mais peixes se reproduzindo, mais famílias pescando e a água mais purificada. $O$ lixo será colocado nas lixeiras e a vegetação crescerá "verde e viçosa"

Por outro lado, outro professor que leciona a disciplina de português usa de uma postura pessimista para relatar seu mapa mental admitindo que no futuro a barragem estará totalmente degradada:

"Não haverá mais nada, além da lembrança"

A professora atribui a grave situação futura ao uso abusivo para o turismo, ao descaso e a falta de consciência das pessoas, vindo tornar o ambiente desequilibrado. Pode-se observar que no seu mapa mental (figura 04), não foi representado nenhuma forma de vida e a barragem apresenta-se completamente seca. 


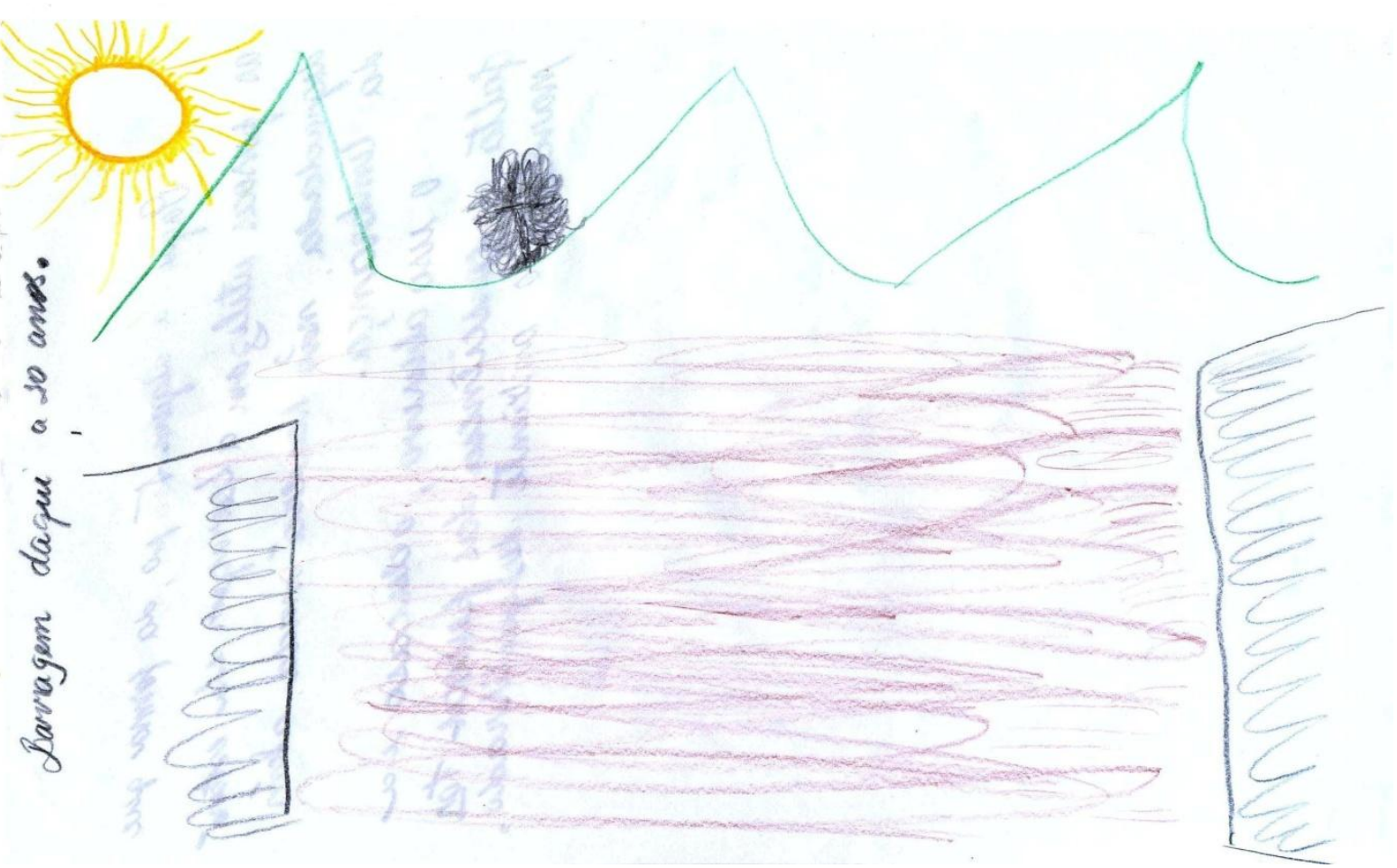

Figura 04. Mapa mental para uma situação futura da barragem Cajaíba denotando pessimismo.

A professora de educação física cita que:

"Deve-se pensar de forma otimista, que as pessoas irão se preocupar com o meio ambiente e busquem formas de solucionar os problemas, possibilitando que a barragem volte a ter sua água limpa"

\section{CONCLUSÃO}

Vale destacar que de acordo com os mapas mentais representados pelos professores, fica evidente a preocupação com o corpo d'água presente no povoado e foco de nosso estudo, tanto com a situação atual como também, referente ao futuro, ficando evidente o anseio pela adoção de estratégias de recuperação e preservação do recurso hídrico. Pode-se observar através do contato via-projeto, que as atividades geraram certo "despertar" junto aos docentes da importância de se promover atividades visando sensibilizar alunos e indiretamente seus familiares para postura mais harmoniosa relacionado ao meio ambiente, e principalmente o corpo d'água em questão. 
COSTA \& MAROTI, v(11), no 11, p. 2379 - 2388, JAN-ABR 2013.

Monografias Ambientais

RENOANFSM

(e-ISSN: 2236-1308)

\section{REFERENCIAL BIBLIOGRÁFICO}

BARRAZA, L. Children's Drawings About the Environment. Environmental Education Research. Vol 5 no. 1, p 49-66, 1999.

FAGGIONATO, Sandra. Texto situado no site: http://educar.sc.usp.br/biologia/textos/m_a_txt4.html, 2005. Acesso em: 25/03/07.

FERRARA, L. D. A. Olhar periférico: Informação Linguagem, Percepção Ambiental. São Paulo: EDUSP, 1993.

GUARIM, V. L. M. S. Barranco Alto: uma experiência em educação Ambiental. Cuiabá, UFMT, 2002.

GUIMARÃES, S. T. L. Percepção, interpretação e valoração ambiental. Departamento de geografia IGCE-UNESP, Rio Claro, 2007. (Notas de Aula - Disciplina Percepção e Interpretação Ambiental da Profa. Solange Guimarães proferida no curso do CRHEA - Centro de Recursos Hídricos e Ecologia Aplicada).

HIGUCHI, M. I. G.; AZEVEDO, G. C. Educação como processo na construção da cidadania ambiental. Revista Brasileira de Educação Ambiental, Brasília, no. 0, 2004, p.63-70.

IBGE - Instituto Brasileiro de Geografia e Estatística, 2010. Disponível em:

http://www.ibge.gov.br/home/geociencias/cartografia/manual_nocoes/elementos_representacao.html. Acesso em: 10/05/10.

JACOBI, C. M.; FLEURY, L. C.; ROCHA, A. C. C. L. Percepção ambiental em unidades de conservação: experiência com diferentes grupos etários no Parque Estadual da Serra do Rola Moça, MG. Anais do 7o Encontro de Extensão da Universidade Federal de Minas Gerais, Belo Horizonte, 2004.

KRASILCHIK, M. Educação ambiental na escola brasileira - passado, presente e futuro. Revista Ciência e Cultura, Rio de Janeiro, no. 38, 1986, p.1958-1961.

MAROTI, P. S. Educação e Interpretação Ambiental junto à comunidade do entorno de uma unidade de conservação. Tese de Doutorado. São Carlos: PPG-ERN - Universidade Federal de São Carlos, 2002.

MARTINS, A. K. S. As contribuições do estudo do meio para a inserção da educação ambiental no contexto escolar. Trabalho de Monografia. Disciplina Pesquisa e Ensino de Ciências e Biologia, Universidade Federal de Sergipe, 2007.

NIEMEYER, A. M. de. Desenhos e mapas na orientação espacial: pesquisa e ensino de antropologia. IFCH/Unicamp, $n$. $12,1994$.

NIDELCOFF, M. T. A escola e a compreensão da realidade. São Paulo: Brasiliense, 1979.

PONTUSCHKA, N. N. A formação pedagógica do professor de geografia e as práticas interdisciplinares. 1994. $343 f$. Tese (Doutorado em Educação) - Faculdade de Educação, Universidade de São Paulo, São Paulo, 1994. 